\title{
Cardiac Phenotype of Duchenne Muscular Dystrophy: Insights from Cellular Studies
}

\author{
Natalia Shirokova ${ }^{1}$ and Ernst Niggli ${ }^{2}$
}

From the Department of Pharmacology and Physiology ${ }^{1}$, University of Medicine and Dentistry NJMS, Newark 07103, NJ, USA and the Department of Physiology ${ }^{2}$, University of Bern, $\mathrm{CH}$ 3012 Bern, Switzerland.

Running title: cellular pathomechanisms in dystrophic cardiomyopathy

Key words: Dystrophic cardiomyopathy, excitation-contraction coupling, ryanodine receptor, $\mathrm{Ca}^{2+}$ signals

Total word count: 5566 (without references) and 7,548 (with references)

\section{Address correspondence to:}

N. Shirokova, Department of Pharmacology and Physiology, University of Medicine and Dentistry - NJMS, 185 S. Orange Ave., Newark 07103, NJ, USA. E-mail: nshiroko@umdnj.edu, phone: +1 9739728877, fax: +19739727950.

E. Niggli, Department of Physiology, University of Bern, Buhlplatz, CH-3012 Bern, Switzerland. E-mail: niggli@pyl.unibe.ch, phone: +41 316318730, fax: +41 316314611.

\section{Correspondence for editorial processing:}

N. Shirokova

Department of Pharmacology and Physiology

University of Medicine and Dentistry - NJMS

185 S. Orange Ave., Newark 07103, NJ, USA

e-mail: nshiroko@umdni.edu

phone: +1 9739728877

fax: $\quad+19739727950$ 


\begin{abstract}
Dilated cardiomyopathy is a serious and almost inevitable complication of Duchenne Muscular Dystrophy, a devastating and fatal disease of skeletal muscle resulting from the lack of functional dystrophin, a protein linking the cytoskeleton to the extracellular matrix. Ultimately, it leads to congestive heart failure and arrhythmias resulting from both cardiac muscle fibrosis and impaired function of the remaining cardiomyocytes. Here we summarize findings obtained in several laboratories, focussing on cellular mechanisms that result in degradation of cardiac functions in dystrophy.
\end{abstract}




\section{Content}

1. Introduction

2. Genetic and molecular underpinning of DMD

3. Animal models of DMD

3.1. The $m d x$ model

3.2. The utrophin deficient $m d x$ mouse

3.3. The $m d x / M y o D$ deficient double mutant mouse

3.4. Canine models

4. Cellular manifestations of cardiac dystrophy

5. Cellular mechanisms of cardiac dystrophy

5.1. $\mathrm{Ca}^{2+}$ influx pathways

5.1.1. Membrane tears

5.1.2. Stretch-activated channels (SACs) and TRP channels

5.1.3. $\mathrm{Na}^{+}$influx and $\mathrm{NCX}$

5.2. Cellular $\mathrm{Ca}^{2+}$ signal amplification mechanisms

5.2.1. Intracellular and SR luminal $\mathrm{Ca}^{2+}$ concentration

5.2.2. RyR oxidation

5.2.3. RyR nitrosation

5.2.4. Phosphorylation

6. Summary 
Non-standard Abbreviations and Acronyms

$\begin{array}{ll}\text { ACE } & \text { Angiotensin converting enzyme } \\ \text { CaMKII } & \mathrm{Ca}^{2+} / \text { calmodulin-dependent protein kinase II } \\ \text { CaV3 } & \mathrm{Caveolin} \mathrm{3}^{2 \mathrm{Ca}^{2+}} \\ \text { CICR } & \mathrm{Ca}^{2+} \text {-induced } \mathrm{Ca}^{2+} \text { release } \\ \text { DMD } & \text { Duchenne muscular dystrophy } \\ \text { ECC } & \text { Excitation-Contraction Coupling } \\ \text { ISO } & \text { Isoproterenol } \\ \text { NCX } & \mathrm{Na}^{+}-\mathrm{Ca}^{2+} \text { exchanger } \\ \text { NOX } & \text { Nicotinamide adenine dinucleotide phosphate-oxidase }_{\text {NOS }} \text { Nitric oxide synthase } \\ \text { PDE } & \text { Phosphodiesterase } \\ \text { PKA } & \text { Protein kinase A } \\ \text { ROS } & \text { Reactive oxygen species } \\ \text { RNS } & \text { Reactive nitrogen species } \\ \text { RyR } & \text { Ryanodine receptor } \\ \text { SAC } & \text { Stretch-activated channel } \\ \text { SOC } & \text { Store-operated Ca } a^{2+} \text { entry pathways } \\ \text { SERCA } & \text { Sacrcoplasmic reticulum Ca }{ }^{2+} \text { ATP-ase } \\ \text { SR } & \text { Sarcoplasmic reticulum } \\ \text { TRPC } & \text { Transient receptor potential channel }\end{array}$




\section{Introduction}

Duchenne Muscular Dystrophy (DMD) is an inherited lethal muscular disease that affects primarily adolescent males. DMD was named after the French physiologist Guillaume-Benjamin Duchenne who presented several cases of infants with dystrophy in the mid 19th century [1]. DMD is usually diagnosed in early childhood. For a long time it was considered to be predominantly a skeletal muscle illness clinically associated with progressive debilitating muscle weakness, skeletal deformities and breathing disorders. Cardiac complications of this disease became prominent only recently as the life of DMD patients could be prolonged with improved therapies, such as assisted ventilation and corticosteroid treatment. About $95 \%$ of the patients with DMD develop cardiomyopathy by 20 years of age, and for approximately $20 \%$ of these patients it is limiting for survival. Abnormalities in the electrocardiogram and sinus tachycardia are found in a majority of DMD patients at early age. Later, echocardiography reveals motion abnormalities of the left ventricular walls in areas of fibrosis. Progressive spreading of fibrosis throughout the ventricular wall mediates a gradual enlargement of the ventricle, thinning of the wall and consequently a loss of contractility and heart failure. In addition to the dilated cardiac myopathy many DMD patients also develop arrhythmias that may lead to a sudden death [2-4]. Further prolongation of survival and amelioration in the quality of life for DMD patients depends not only on improving skeletal muscle performance but also on the development of therapies that slow down the progression of the cardiac disease and enhance cardiac function. This requires a mechanistic understanding of the nature of the cardiac defects, which can be obtained from studies of the cellular phenotype of the disease. This review focuses on our current view of cellular and molecular pathomechanisms of the dystrophic cardiomyopathy.

\section{Genetic and molecular underpinning of DMD}

To date, 25267 variants of the dystrophin gene are known [5]. The gene is on the Xp21 chromosome locus and with 2.2 megabases is one of the longest human genes known. Skeletal and cardiac muscle of DMD patients either completely lack or express a truncated form of dystrophin, which in muscle is a 427 kDa protein. Alternatively spliced isoforms expressed in a variety of other tissues can be substantially smaller, many are $\sim 70 \mathrm{kDa}$. Dystrophin links the sarcomeric cytoskeleton to a complex of transmembrane proteins (called dystrophin-associated protein complex), which interacts with extracellular matrix [6,7]. In muscle, the dystrophin network covers almost the entire cytoplasmic surface of the plasma membrane. Dystrophin is also present in T-tubular membranes in cardiac myocytes [8,9]. Thus, it is strategically placed to serve in a variety of mechanical roles, such as maintenance of membrane stability and the transduction of mechanical force to the extracellular matrix. Indeed, it is widely accepted that the predominant functional consequence of the lack of dystrophin is an increased cellular vulnerability to mechanical stress associated with muscle contraction. One of the early diagnostic tests of DMD is to determine serum creatine kinase (CK) activity. It is increased in DMD patients as creatine kinase leaks through the plasmalemmal membrane of mechanically damaged dystrophin deficient muscle cells. Optical methods also detected accumulation of large molecular weight indicators inside dystrophic muscle cells getting inside through the 
unstable cellular membrane [10-12]. However, it should be noted that the direct measurement of tensile strength of normal and dystrophic sarcolemma did not reveal a significant difference [13] and the increase in intracellular $\mathrm{Ca}^{2+}$ levels, rather the absence of dystrophin was proposed to underly the reduced resilience of the plasmalemma [14]. The precise molecular underpinnings of the membrane vulnerability resulting from the lack of dystrophin are, however, poorly understood at present [7]. In principle, the mechanism could be direct and mechanical, or indirect via $\mathrm{Ca}^{2+}$ overload or oxidative stress.

\section{Animal models of DMD}

\subsection{The $m d x$ mouse}

The $m d x$ mouse is a strain of mice which arose from a spontaneous mutation $(m d x)$ in inbred C57BL mice. In more recently identified dystrophin mutants, such as the $m d x^{2 \mathrm{cv}} m d x^{4 \mathrm{cv}} m d x^{5 \mathrm{cv}}$ mice, the spectrum and tissue distribution of the affected isoforms is different, usually more wide spread, and there are fewer mutation reversions [15]. Like DMD patients, $m d x$ mice have a total loss of functional dystrophin from the muscle tissue. In contrast to humans, they have a less severe phenotype and a more slowly developing cardiac disease with a near normal life span. Because of their mild phenotype, there were initially some difficulties to validate $m d x$ mice as an appropriate model of cardiac dystrophy. However, recent studies clearly demonstrated that $m d x$ mice develop dystrophic cardiomyopathy later in life. Hearts of 2 month old $m d x$ mice seemed to have normal ventricular cytosolic function and normal echocardiograms [16]. Nevertheless, even these young $m d x$ hearts are more susceptible to damage when subjected to mechanical overload [17]. By 8 months of age, hearts from $m d x$ mice are dilated, hypertrophied, somewhat fibrotic and poorly contracting [16,18]. Additionally, electrocardiographic (ECG) deviations gradually increase in $m d x$ mice and by the age of 6 months significant abnormalities are revealed in the cardiac conduction system [19,20]. Altogether, $m d x$ mice have some but not all symptoms of DMD cardiomyopathy. The manifestation is not as pronounced as in DMD and depends on mechanical challenges. However, because of their slowly developing phenotype $m d x$ mice can be a useful model for studies of the progression of DMD and can help to identify the cellular sequence of events leading from the genetic defect (lack of functional dystrophin) to the onset of cardiac disease.

\subsection{The utrophin deficient $m d x$ mouse}

Utrophin is a cytoskeletal protein which was originally described as dystrophin-like in 1989 because of its partial homology [21]. It is widely expressed in differentiating skeletal muscle with the same cellular distribution as dystrophin. In adult tissue utrophin disappears from the sarcolemma, being replaced by dystrophin and it remains primarily localized to the neuromuscular junction. Utrophin expression dramatically increases in muscle from DMD patients and in $m d x$ mice. It is believed that utrophin can partially compensate for the loss of dystrophin and to some extent explain the mild phenotype of $m d x$ muscle (especially in skeletal muscle). Mdx/utrn ${ }^{--}$double knockout mice (DKO) exhibit most of the clinical signs of DMD 
patients, such as short stature, kyphosis, limb weakness and breathing problems by 6 weeks of age [22]. All DKO mice succumb to premature death by 20 weeks of age. Compared to senescent $m d x$ mice, their cardiac dystrophic phenotype is similar, but it's onset is much earlier [23]. By 10 weeks of age DKO mice not only exhibit multiple histological defects, such as myocyte degeneration, inflammation and some fibrosis, but also abnormal ECGs and contractile dysfunction [24]. Therefore, the $m d x / u_{t r n}{ }^{-/}$DKO mouse is another useful model of DMD. However, DKO mice are more difficult to breed. The homozygous animals do not survive birth and the heterozygous mice have a low rate of live-born descendants. In addition, the dramatically reduced life span of these mice may limit exposure to extrinsic influences, which may otherwise contribute to the DMD cardiomyopathy in a relevant manner [22,24].

\subsection{The $m d x / M y o D$ deficient double mutant mouse}

The myogenic differentiation factor $\mathrm{D}(\mathrm{MyoD})$ plays a key role in skeletal muscle differentiation and regeneration. $M d x / M_{y o D}{ }^{-/}$mice display not only a pronounced skeletal muscle myopathy but also severe cardiomyopathy [25]. Because MyoD is not expressed in heart this peculiar cardiomyopathy is attributed to the progression of skeletal muscle disease. This evidence also supports the idea that cardiac abnormalities in DMD may not only be a result of the dystrophin deficiency in heart tissue, but also a consequence of skeletal muscle damage, which initiates stress-activated signaling pathways. Histological studies revealed large areas of fibrosis, associated with hypertrophied and necrotic myocytes. Notably, as in DMD hearts, the epicardial region of the left ventricle is prominently affected. It was suggested that the $m d x / \mathrm{MyoD}^{-/-}$mouse has the most faithful disease representation among the available models of DMD cardiomyopathy [25]. However, more functional studies are required to substantiate this claim.

\subsection{Canine models}

Mutations of the canine DMD gene were identified in Golden Retriever, Rottweiler, German Short-Hair Pointer, and Cavalier King Charles Spaniels (reviewed in [26]). Golden Retriever Muscular Dystrophy (GRDM) is the most thoroughly studied. Extensive muscle degeneration and necrosis were identified in GRDM from birth onwards and severe muscle fibrosis develops by 6 months of age. Respiratory failure or cardiomyopathy was frequently observed even at younger ages. The skeletal and cardiac characteristics of GRMD resemble those of human DMD more than those of mouse models. The genetic background and body size of the Golden Retriever is also closer to humans. Therefore, GRDM has been considered to be a useful animal model for human DMD. However, the size of the dog makes it difficult to maintain a colony. Hence this animal model is mostly used in late stages of preclinical studies of pharmacological interventions targeted to DMD.

Overall, $m d x$ mice and some of its additional mutant strains remain the most widely used DMD model for studies of cellular pathomechanisms of dystrophy. The $m d x$ mouse is commercially available, is easy to breed and maintain, has a long life expectancy and a low rate of sudden 
death. Most of the results summarized in this review were obtained using $m d x$ mice as a DMD model.

\section{Cellular manifestations of cardiac dystrophy}

Ventricular cardiomyocytes isolated from $m d x$ mouse heart exhibit a number of distinct characteristics compared to cells from wild type animals: 1) their plasmalemmal membrane is more fragile [10,11]; 2) ionic fluxes across the membrane are increased [11,27]; 3) resting cytosolic $\mathrm{Ca}^{2+}$ and $\mathrm{Na}^{+}$levels are elevated [27-29]; 4) intracellular $\mathrm{Ca}^{2+}$ responses to mechanical challenges are enhanced $[10,28,30]$; 5) excitation-contraction coupling (EC-coupling) is hypersensitive [31]; and 6) the intracellular and mitochondrial redox state is shifted towards a more oxidative state [28,29,32]. In addition, in myocytes isolated from animals with more advanced stages of the disease mitochondria may undergo irreversible depolarizations and loss of $\mathrm{Ca}^{2+}$ from the matrix, indicating severe mitochondrial dysfunctions [28]. The findings listed above are pieces of the puzzle identified by current research. They have to be critically evaluated and put together in order to understand the cellular pathomechanisms driving progression of cardiac dystrophy downstream of this initial injuries.

\section{Cellular mechanisms of cardiac dystrophy}

As mentioned above, $m d x$ hearts are more susceptible to damage when subjected to mechanical overload [17]. Histological examination revealed replacement of muscle with connective tissue (fibrosis), a clear indication of muscle wasting. Furthermore, analysis on the cellular level showed the presence of necrotic and apoptotic muscle cells [33]. Pharmacological and genetic inhibition of cyclophilin $\mathrm{D}$ and thus mitochondria-linked cell death in mdx mice attenuates muscular dystrophy [34]. Therefore, cell death and fibrosis are end points of the dystrophic damage in tissue. But what initiates the sequence of events ultimately destroying the cells? A large body of research and a combination of the "mechanical" and the "Ca" hypothesis of skeletal muscular dystrophy suggests that the augmented $\mathrm{Ca}^{2+}$ influx through fragile cellular membrane results in elevated intracellular $\mathrm{Ca}^{2+}$ levels, at least in some of the $\mathrm{Ca}^{2+}$ signaling microdomains. Together, these acute but repeatedly occurring signaling events

may lead to serious cellular damage in the long-term. Downstream activation of $\mathrm{Ca}^{2+}$ dependent proteases, release of caspases and activation of associated pathways may eventually lead to untimely cell death by apoptosis and/or necrosis (as depicted at Diagram 1). Such events may in turn be the starting point for the fibrotic patches, which can be observed in dystrophic cardiac muscle tissue [35].

\section{1. $\mathrm{Ca}^{2+}$ influx pathways}

There are several reports of increased $\mathrm{Ca}^{2+}$ conductance in dystrophic muscle. Multiple $\mathrm{Ca}^{2+}$ entry pathways were examined experimentally. These studies were focused on membrane tears 
(e.g. microruptures, $[10,11,28]$ ), stretch-activated (SACs) and stretch-inactivated channels $[11,27,36,37])$, store-operated $\mathrm{Ca}^{2+}$ entry pathways (SOCE, [37]), L-type $\mathrm{Ca}^{2+}$ channels [38] and transient receptor potential channels (TRP channels, $[37,39,40])$. Since some of these pathways also allow $\mathrm{Na}^{+}$to enter the cells (e.g. SACs, tears, TRP channels), the reverse mode of $\mathrm{Na}^{+}-$ $\mathrm{Ca}^{2+}$ exchange (NCX) has also been proposed as a potential source for cytosolic $\mathrm{Ca}^{2+}$ entry [11].

\subsubsection{Membrane ruptures}

The existence of membrane ruptures or tears permeable to even relatively large molecules such as albumin was first found in skeletal muscle [41]. Membrane tears occur more often in $m d x$ muscle fibers but are quickly resealable in most cases [37]. It seems that $m d x$ cardiac muscle is also predisposed to the formation of microruptures. A substantial stretch-dependent internalization of the FM1-43 lipophilic fluorescent indicator was detected in dystrophic cardiomyocytes $[10,11]$. Evans Blue dye leakage into myocytes of the left ventricle was significantly larger in $m d x$ mice [12]. Moreover, in vivo treatment of $m d x$ mice or preincubation of isolated $m d x$ cardiac myocytes with the membrane sealant "Poloxamer 188" corrected increases in intracellular $\mathrm{Ca}^{2+}$ levels resulting from passive and acute stretch. It also improved the hemodynamic performance of the left ventricle, consistent with a reduction in the formation of microruptures $[10,11,28]$. The copolymer Poloxamer 188 has previously been shown to insert into artificial lipid monolayers and repair damaged biological membranes when needed [42].

\subsubsection{Stretch-activated channels (SACs) and TRP channels}

Inhibitors of SACs such as $\mathrm{Gd}^{3+}$, streptomycin and GsMTx-4 significantly inhibited stretchinduced intracellular $\mathrm{Ca}^{2+}$ increases in cardiomyocytes [11,27]. The subunit composition of SACs is not yet known, but several TRP channels have been suggested to participate. This includes TRPC1, TRPC6 and TRPV2. Depending on their environment, they may form mechanosensitive non-selective cation channels $[40,43,44]$, which could be parts or subunits of SACs. They are present in T-tubules of cardiomyocytes and their expression is significantly increased in dilated $m d x$ heart $[27,45]$. TRPC1 is targeted to T-tubules by caveolin-3, a scaffolding protein of caveolae, and both proteins are linked to Src-kinase. Caveolin-3 and Srckinase are also upregulated in $m d x$ heart and $\mathrm{Ca}^{2+}$ influx through TRPC1 is significantly increased when Src is activated by reactive oxygen species (ROS, see cross-talk chapter below) [39]. Moreover, overexpression of caveolin-3 in cardiac and skeletal muscle tissue causes defects similar to DMD $[46,47]$. Taken together the evidence above suggests that the Caveolin-3-TRPC1-Src complex is likely to be part of a stretch activated $\mathrm{Ca}^{2+}$ (and $\mathrm{Na}^{+}$) influx pathway in dystrophy. Skeletal muscle from transgenic mice overexpressing TRPC3 channels exhibit increased $\mathrm{Ca}^{2+}$ influx via SOCE and the mice themselves develop severe muscle disease reminiscent of DMD. To the contrary, crossing delta-sarcoglycan deletion mice $\left(\mathrm{Scgd}^{-1}\right)$, another mouse model of muscular dystrophy, with transgenic mice that overexpress a dominant negative mutant of TRPC6 attenuates muscular dystrophy [48]. It is possible that overexpression of non-conducting mutants of TRPC6 impede the activity of heterotetrameric 
endogenous TRP complexes, antagonizes SOCE and partially rescues dystrophy. Similarly, overexpressing a dominant negative mutant of TRPV2 or ablation of TRPC1 protected dystrophic skeletal muscle fibers from the damage caused by eccentric contractions $[40,49]$.

\subsection{3. $\mathrm{Na}^{+}$influx and $\mathrm{NCX}$}

A secondary $\mathrm{Ca}^{2+}$ influx pathway, the $\mathrm{Na}^{+}-\mathrm{Ca}^{2+}$ exchanger which in cardiac muscle has a large transport capacity, was also held responsible for enhanced $\mathrm{Ca}^{2+}$ influx in $m d x$ cardiomyocytes. It contributes to $\mathrm{Ca}^{2+}$ entry in exchange for $\mathrm{Na}^{+}$that had previously entered via primary stressinduced pathways (microruptures and SACs) [11] or via voltage-dependent $\mathrm{Na}^{+}$channels, which appear to be stretch sensitive, but down regulated and redistributed in $m d x$ cardiomyocytes $[50,51]$.

Overall, stretch-induced $\mathrm{Ca}^{2+}$ influx through several transmembrane pathways are undoubtedly elevated in dystrophic cardiomyocytes. Exact mechanisms underlying upregulation of these pathways remain elusive. Oxidative stress may be partly responsible, because it can cause lipid peroxidation of sarcolemmal membrane and increased occurrence of microruptures [37]. Moreover, oxidation of disulfide bonds near the pore of TRP channels is thought to increase $\mathrm{Ca}^{2+}$ influx through some of these channels [52]. The magnitude of the total $\mathrm{Ca}^{2+}$ influx appears to be relatively small and not sufficient to entirely explain the excessive intracellular $\mathrm{Ca}^{2+}$ responses to mechanical stress observed even early during the development of the disease $[10,11,28,30]$. It has also been reported that at different stages of dystrophic cardiomyopathy the cellular phenotype displays hypersensitive EC-coupling [31], increased $\mathrm{Ca}^{2+}$ leak from the sarcoplasmic reticulum (SR) and reduced SR $\mathrm{Ca}^{2+}$ load [53,54]. All together, these features reflect significant changes in intracellular $\mathrm{Ca}^{2+}$ homeostasis and point to abnormally sensitive $\mathrm{Ca}^{2+}$-induced $\mathrm{Ca}^{2+}$ release $(\mathrm{CICR})$ from the SR via RyR channels.

\subsection{Cellular $\mathrm{Ca}^{2+}$ signal amplification mechanisms}

Changes in intracellular $\mathrm{Ca}^{2+}$ cycling that are either causal or adaptive were observed in diverse models of cardiac disease, including several forms of heart failure [55]. Frequently, $\mathrm{Ca}^{2+}$ signaling proteins showed altered levels of expression, most notably the SR $\mathrm{Ca}^{2+}$ ATPase (a.k.a. SERCA pump), which commonly has a low abundance in diseased cardiac muscle. Moreover, functional changes in $\mathrm{Ca}^{2+}$ handling were often linked to posttranslational modifications of $\mathrm{Ca}^{2+}$ signaling proteins. An important example are the RyRs, which can undergo various modifications, such as oxidation, S-nitrosation (sometimes referred to as Snitrosylation) and S-glutathionylation, PKA- or CaMKII-dependent phosphorylation [56-58] (shown on Diagram 2). The contribution of these posttranslational RyR modifications, their functional consequences and disease causing potential are still controversial and need to be clarified for each particular disorder. Since all of the modifications mentioned above are likely to increase the open probability of RyRs, the sensitized CICR mechanisms observed in $m d x$ cardiomyocytes could be the consequence of any (or a combination of several) of those 
modifications. Similar changes in RyR sensitivity to cytosolic $\mathrm{Ca}^{2+}$ may also be the result of increased intracellular or SR luminal $\mathrm{Ca}^{2+}$ levels. Of note, isolated RyR hypersensitivity can lead to enhanced diastolic SR $\mathrm{Ca}^{2+}$ leak, which may in turn result in a reduced $\mathrm{SR} \mathrm{Ca}^{2+}$ content. This reciprocal relationship between RyR sensitivity and $S R$ luminal $\mathrm{Ca}^{2+}$ leads, within limits, to an autoregulatory and stabilizing CICR behavior [59]. However, in the case of dystrophic cardiomyopathy, this feature may be overridden by the slightly elevated sarcolemmal $\mathrm{Ca}^{2+}$ leak into the cell (see above).

\subsubsection{Intracellular and SR luminal $\mathrm{Ca}^{2+}$ concentration}

Despite the small but permanent $\mathrm{Ca}^{2+}$ leak into the cardiomyocytes, significant elevations in $\left[\mathrm{Ca}^{2+}\right]_{\text {cyto }}$ were detected only in cells isolated from older $m d x$ mice already showing some cardiac symptoms on the organ level [27]. Similarly, a significant decrease in SR luminal [ $\mathrm{Ca}^{2+}$ ] was also only observed after the onset of cardiac manifestations and at final stages of the disease. In contrast, the stress induced augmented $\mathrm{Ca}^{2+}$ signaling and hypersensitive EC-coupling were already present in myocytes isolated from $m d x$ pups [60]. Moreover, hearts of 2 months old $m d x$ mice are already abnormally vulnerable to mechanical stress and workload-induced damage [17]. Based on this sequence of events, it is unlikely that changes in $\left[\mathrm{Ca}^{2+}\right]_{\text {cyto }}$ or SR $\mathrm{Ca}^{2+}$ load, which manifest only later in the onset of the dystrophic cardiomyopathy, are driving the early cellular abnormalities in $m d x$ mice. Rather they are part of a slowly developing cellular adaptive response, which only later becomes maladaptive.

\subsubsection{RyR oxidation}

A multitude of cardiac diseases is accompanied by oxidative stress, and the RyRs are known to be favored targets for thiol oxidation [61]. It is already well established that oxidative stress contributes to skeletal muscle damage in DMD $[62,63]$. Emerging evidence suggests that this may as well be the case for cardiac muscle tissue. Moreover, oxidative stress may serve as a pathomechanism that is at least as important for dystrophic cardiomyopathy as the damage caused by the abnormalities of $\mathrm{Ca}^{2+}$ signaling, particularly at early stages of the disease [60]. It appears that the "mechano- $\mathrm{Ca}^{2+}$ hypothesis" of cardiac dystrophy should be significantly modified as previously proposed for skeletal muscle with the introduction of a "two-hit hypothesis of dystrophy" [64]. In cardiomyocytes isolated from $m d x$ animals, ROS production was noted to be abnormally high and ROS scavengers could prevent most of the acute $\mathrm{Ca}^{2+}$ signaling alterations, suggesting an important role of oxidative stress [28,30,60]. Moreover, invivo treatment of $m d x$ mice with the antioxidant $\mathrm{N}$-acetylcysteine (NAC) reduced ROS levels, normalized intracellular $\mathrm{Ca}^{2+}$ homeostasis, improved myofilament function and reduced cardiac inflammation and fibrosis [32]. Similar to skeletal muscle, the major source of ROS in dystrophic cardiac tissue seems to be $\mathrm{NAD}(\mathrm{P}) \mathrm{H}$ oxidase (NOX), especially during acute mechanical stress and at the early stages of the disease (see Diagram 1). Expression levels of several subunits of the membrane-bound NOX2 isoform are elevated in dystrophic heart and the activity of the enzyme is increased. Consistent with the high expression levels, the ROS production in cardiac homogenate was reduced by the NOX inhibitor DPI, but not by oxypurinol or rotenone (inhibitors 
of ROS production by xanthine oxidase and mitochondria, respectively) [32]. At the single cell level, the acute increase in ROS production prompted by mechanical stretch was abolished by NOX blockers, either apocynin, DPI or the specific peptide gp91ds that prevents the assembly of NOX2 subunits [28,30]. In addition, a stretch-induced increase in ROS generation was completely abolished in $\mathrm{NOX}^{-/-}$mice. The augmented intracellular $\mathrm{Ca}^{2+}$ responses to mechanical challenge and hypersensitivity of EC-coupling were normalized by both, ROS scavengers and NOX blockers [28,30,31] suggesting that oxidation of RyRs is one of the early posttranslational modifications in dystrophy. There are several tentative mechanisms possibly underlying enhanced NOX activity in dystrophy. NOX could be activated via phosphorylation by $\mathrm{Ca}^{2+}$ sensitive PKC [65-67]. PKC could also be turned on via Angiotensin II receptor signaling, which seems to be activated by stretch, even in the absence of an agonist [68]. A direct activation of NOX by mechanical stretch exerted by the intracellular tubulin network has also been proposed [30]. While the disease progresses further, it is likely that additional ROS sources, such as mitochondria, will also contribute to the oxidative stress. Elevated intracellular $\mathrm{Ca}^{2+}$ levels could lead to mitochondrial $\mathrm{Ca}^{2+}$ overload, increased ROS leak to the cytosol and finally to mitochondrial dysfunction [28]. It should be mentioned again that oxidative stress also intensifies plasmalemmal $\mathrm{Ca}^{2+}$ influx (e.g. via membrane lipid peroxidation and activation of TRP channels, [39,62]). In addition, it reduces contractility via direct effect on contractile proteins [62], both factors contributing to deterioration in dystrophy.

\subsubsection{RyR nitrosation}

Relocalization of neuronal nitric oxide synthase (nNOS, NOS1), which is a member of the dystrophin associated protein complex, from the plasmalemma to the cytosol along with the dysregulation of the NO signaling pathway was also held accountable for the development of skeletal muscle pathology in DMD [64]. In addition, it has been reported that hyper-S-nitrosation of skeletal muscle RyR1 may be due to an increased activity of inducible NO synthase (iNOS, NOS2). Subsequent depletion of the stabilizing protein calstabin-1 from the RyR1 complex result in leaky $\mathrm{Ca}^{2+}$ release channels and intracellular $\mathrm{Ca}^{2+}$ overload [69]. A similar sequence of events has also been suggested to play an important role in the dystrophic heart [53]. RyRs in hearts of $m d x$ mice 35 days and older were found to be hyper-S-nitrosated and calstabin-2 was depleted from the RyR complex. This could be reversed by treatment of $m d x$ mice with the RyR channel stabilizer "rycal" S107 or NAC. The latter also indicated that S-nitrosative modification of cysteines on the RyRs may occur via conversion of NO to peroxynitrite after a chemical reaction with superoxide anion. In contrast to skeletal muscle where the RyR nitrosation in dystrophy closely follows the muscle inflammation and up-regulation of iNOS, the cellular pathway leading to hyper-S-nitrosation of RyRs in cardiac dystrophy are yet to be elucidated. This scenario may be quite complex as the levels of SR bound NOS1 and caveolae-associated endothelial NOS (eNOS, NOS3) are reduced in hearts of dystrophic mice and dogs $[19,70]$ while the levels of inflammatory-induced NOS2 are increased only in adult (180 days old) $m d x$ mice [53]. It is conceivable that oxidative stress and extensive ROS production by NOX are driving forces for RyR S-nitrosation via overproduction of peroxynitrite, at least in early stages of the cardiomyopathy. The action of NO within heart cells goes far beyond its involvement in 
protein S-nitrosation, as it also serves as an important signaling molecule. In particular, NO activates guanylyl cyclase to produce cGMP, a second messenger with multiple targets in heart, including protein kinase $\mathrm{G}$ and proteins directly involved in intracellular $\mathrm{Ca}^{2+}$ homeostasis [71]. Reduced NOS activity in dystrophy may therefore down regulate cGMP-signaling pathways. Consistent with this possibility, dystrophic $m d x$ mice with overexpression of constitutively active guanylyl cyclase were found to have improved cellular integrity, myocardial contractility and energy metabolism [72]. Moreover, treatment of young (6-week-old) $m d x$ mice with the phosphodiesterase 5 inhibitor sildenafil, which slows down cGMP breakdown, had a similar beneficial effect on cardiac function [72]. These in-vivo studies support the notion that alterations in NO signaling are key contributors to cardiac dystrophy, although the cellular pathways still need to be clarified.

\subsubsection{Phosphorylation}

The RyR tetramer forms a large macromolecular complex associated, among others, with protein kinases (PKA and CaMKII) and phosphatases (1 and 2A). Some of these enzymes are tethered to and therefore held near the RyRs by anchoring proteins. Research on a potential role of the RyRs in various cardiac diseases has burgeoned within the last decade, partly driven by the discovery of RyR mutations [73] and post-translational modifications. Using mainly biochemical and molecular biology approaches, serine 2808 and 2830 on the RyR have been identified as possible phosphorylation sites for protein kinase A (PKA), and serine 2814 for CaMKII (for reviews see [56-58]). Numerous studies have suggested functional consequences of these phosphorylation sites on the RyRs, from the molecular to the cellular level, but also in various in-vivo models of cardiac diseases. Changes of RyR phosphorylation status were as well being considered as a factor possibly aggravating dystrophic cardiomyopathy. However, an initial study found no significant changes in phosphorylation of RyR on Ser-2808 [53] in $m d x$ mice up to 6 months of age. In contrast, follow up studies revealed a significant increase in RyR phosphorylation by PKA but only in senescent 15 months old animals. At the same time, no changes in PKA dependent phosphorylation of phospholamban, a regulatory protein of the SR $\mathrm{Ca}^{2+}$ ATPase, could be detected. This suggests a local modification of the RyR phosphorylation by more active PKA (or less active phosphatase) tethered to the RyR macromolecular complex [74]. Moreover, cross-breeding of $m d x$ mice with RyR2-S2808A mice, in which the PKA phosphorylation site S2808 on RyR2 is ablated by alanine substitution, significantly improved cardiac performance and rescued function, even in younger animals [74]. At the cellular level, $\mathrm{SR} \mathrm{Ca}{ }^{2+}$ leak was lowered, and ISO-induced $\mathrm{SR} \mathrm{Ca}^{2+}$ release events (e.g. $\mathrm{Ca}^{2+}$ waves) after rapid pacing were eliminated in myocytes from 3-4 month old $m d x$-S2808A mice. Sarcolemmal integrity was also improved probably as a result of ameliorated intracellular $\mathrm{Ca}^{2+}$ signaling [14]. There are also some reports of CaMKII involvement in the cardiac pathology of dystrophy. This would be expected to play a role, since the CaMKII is known to be activated independently of $\mathrm{Ca}^{2+}$ by ROS [75]. A preliminary report indicates that cross-breeding of $m d x$ mice with RyR2S2814A mice, in which the CaMKII phosphorylation site is ablated, prevents spontaneous SR $\mathrm{Ca}^{2+}$ release and sustained ventricular tachycardia following burst pacing [76]. Recent work on CaMKII suggests that this enzyme plays a pivotal role in the development of cardiac dystrophy. 
The presence of the oxidized (i.e. activated [75]) form of CaMKII and phosphorylation of RyR on Ser-2814 (but not on Ser-2808) were significantly increased in cardiac tissue isolated from $m d x$ pups [60]. Moreover, the augmented intracellular $\mathrm{Ca}^{2+}$ responses to mechanical stress and hypersensitivity of EC-coupling were normalized by various CaMKII (but not PKA and NOS) inhibitors [60]. Taken together, these results reveal a successive time-dependent evolution of the prominent disease pathomechanisms in dystrophic hearts. The in-vivo crossbreeding studies confirm that RyR modifications by CaMKII and PKA phosphorylation are driving the development of the disease.

Overall, there is increasing evidence indicating a pivotal role of oxidative stress in the development and progression of cardiac dystrophy (see Diagram 2). It seems that NOX derived ROS signaling has a significant downstream impact on $\mathrm{Ca}^{2+}$ signaling proteins including RyRs. RyR oxidation is followed by phosphorylation, first by CaMKII and later by PKA. Nitrosation synergistically contributes to abnormal cellular $\mathrm{Ca}^{2+}$ signals and to the degradation of cardiomyocyte function. At the terminal stages of cardiac dystrophy RyR hypersensitivity together with the sarcolemmal $\mathrm{Ca}^{2+}$ influx results in a serious increase in $\mathrm{SR} \mathrm{Ca}{ }^{2+}$ leak accompanied by cytosolic and mitochondrial $\mathrm{Ca}^{2+}$ overload $[27,28,60]$. It seems that the latter may be an important turning point which initiates necrotic and apoptotic processes culminating in the loss of functional myocytes, development of cardiac fibrosis and reduction in cardiac contractility [16]. In parallel, the elevated and unbalanced SR $\mathrm{Ca}^{2+}$ leak leads to a depletion of $\mathrm{SR} \mathrm{Ca}^{2+}$ content, which will in turn lower $\mathrm{Ca}^{2+}$ transients, thus contributing to diminished force production by the surviving cardiomyocytes. In combination with the fibrosis, this could eventually impair cardiac contractility further, leading to cardiac failure.

\section{Summary}

There are several main conclusions which can be drawn from the studies reviewed above. It is becoming more and more clear that several pathomechanisms are involved in the cellular damage initiated by the lack of dystrophin, in both skeletal and cardiac muscle. During the slow progression of the cardiomyopathy, the activation of these damaging cellular pathways is orchestrated in an ever changing pattern and severity. This may arise from progressively accumulating mechanical damage to the cells, but also from initially adaptive and later maladaptive remodeling of the cardiac muscle cells. Crosstalk between several of the known pathomechanisms and $\mathrm{Ca}^{2+}$ signaling pathways may be instrumental for the time-dependent evolution of the disease phenotype. If a similar scenario leads to dystrophic cardiomyopathy in human patients, this complexity might have repercussions for the development of novel therapeutic approaches. At present, there are several preclinical and clinical trials ongoing (e.g. treatment with antioxidants, PDE inhibitors, ACE and Ang II receptor inhibitors, $\beta$-blockers, membrane sealants, mitochondrial stabilizers). Each trial is targeting a specific mechanism thought to be of key importance for muscular dystrophy. However, it might be more prudent to apply combinational therapies targeting multiple cellular pathologies simultaneously, and to adapt the treatment regime to the time-dependent prevalence of each of the pathways. For the 
development of such multi-pronged treatment plans a more detailed understanding of the basic pathomechanisms will be decisive.

\section{Acknowledgements}

This work was supported by NIH (HL093342 and AR053933 to N.Sh.), SNF (31-132689 and 31109693 to E.N.) and Swiss Foundation for Research on Muscle Diseases (to E.N. and N.Sh.). We thank Drs. Krista Blackwell and Larry Gaspers for comments on the manuscript. 


\section{Figure legends}

Diagram 1: Damage and cell death pathways in Dystrophy. The abnormally high activity of several signaling pathways, such as ROS/RNS, hyperphosphorylation and $\mathrm{Ca}^{2+}$ signals, triggers mitochondrial damage pathways which ultimately may culminate in apoptotic or necrotic cell death.

Diagram 2: Signaling pathways involved in Dystrophy. The diagram shows the main building blocks of cardiac $\mathrm{Ca}^{2+}$ signaling and EC-coupling. This is combined with the sources, pathways and targets of the pathomechanisms relevant for alterations of $\mathrm{Ca}^{2+}$ signaling in dystrophic cardiomyopathy.

Green lines: pathways of oxidative and nitrosative signals (ROS/RNS). Red lines: pathways of protein phosphorylation signals. Solid lines depict pivotal and dashed lines depict secondary pathways. Dotted lines indicate additional targets of phosphorylation. Abbreviations not explained in the review: Cav3: caveolin-3; $\mathrm{NaC}$ : voltage-dependent $\mathrm{Na}^{+}$channel. LTCC: L-type $\mathrm{Ca}^{2+}$ channel. AC: adenylate cyclase; MR: membrane ruptures; HNX: mitochondrial protonsodium exchanger; $\mathrm{MCU}$ : mitochondrial $\mathrm{Ca}^{2+}$ uniporter; ANT: mitochondrial translocase. 


\section{References}

[1] $\square$ Clarac F, Massion J, Smith AM. Duchenne, Charcot and Babinski, three neurologists of La Salpetrière Hospital, and their contribution to concepts of the central organization of motor synergy. J Physiol Paris 2009;103:361-76.

[2] $\square$ Finsterer J, Stöllberge C. The heart in human dystrophinopathies. Cardiology 2003;99:119.

[3] $\square$ Hermans MCE, Pinto YM, Merkies ISJ, de DieSmulders CEM, Crijns HJGM, Faber CG. Hereditary muscular dystrophies and the heart. Neuromuscul Disord 2010;20:479-92.

[4] Yilmaz A, Sechem U. Cardiac involvement in muscular dystrophy: advances in diagnosis and therapy. Heart 2012;98:420-9.

[5] $\square$ AartsmaRus A, Van Deutekom JCT, Fokkema IF, Van Ommen G-JB, Dunnen Den JT. Entries in the Leiden Duchenne muscular dystrophy mutation database: An overview of mutation types and paradoxical cases that confirm the reading-frame rule. Muscle Nerve 2006;34:135-44.

[6] Hoffman EP, Brown RH, Kunkel LM. Dystrophin: the protein product of the Duchenne muscular dystrophy locus. Cell 1987;51:919-28.

[7] $\square$ Ervasti JM, Campbell KP. A role for the dystrophin-glycoprotein complex as a transmembrane linker between laminin and actin. J Cell Biol 1993;122:809-23.

[8] Kaprielian RR, Stevenson S, Rothery SM, Cullen MJ, Severs NJ. Distinct patterns of dystrophin organization in myocyte sarcolemma and transverse tubules of normal and diseased human myocardium. Circulation 2000;101:2586-94.

[9] $\square$ Kaprielian RR, Severs NJ. Dystrophin and the cardiomyocyte membrane cytoskeleton in the healthy and failing heart. Heart Fail Rev 2000;5:221-38.

$[10] \square$ Yasuda S, Townsend D, Michele DE, Favre EG, Day SM, Metzger JM. Dystrophic heart failure blocked by membrane sealant poloxamer. Nat Cell Biol 2005;436:1025-9.

[11] Fanchaouy M, Polakova E, Jung C, Ogrodnik J, Shirokova N, Niggli E Pathways of abnormal stress-induced $\mathrm{Ca}^{2+}$ influx into dystrophic $m d x$ cardiomyocytes. Cell Calcium 2009;46:114-21.

[12] $\square$ Van Erp C, Loch D, Laws N, Trebbin A, Hoey AJ. Timeline of cardiac dystrophy in 318month-old MDX mice. Muscle Nerve 2010;42:504-13. 
[13] $\square$ Hutter OF, Burton FL, Bovell DL. Mechanical properties of normal and mdx mouse sarcolemma: Bearing on function of dystrophin. J Muscle Res Cell Motil 1991;12:585-9.

$[14] \square$ Nichol JA, Hutter OF. Ca ${ }^{2+}$ loading reduces the tensile strength of sarcolemmal vesicles shed from rabbit muscle. J. Physiol 1996;493:199-209.

[15] $\square$ Im WB, Phelps SF, Copen EH, Adams EG, Slightom JL, Chamberlain JS. Differential expression of dystrophin isoforms in strains of $\mathrm{mdx}$ mice with different mutations. Hum Mol Genet 1996;5:1149-53.

[16] $\square$ Quinlan JG, Hahn HS, Wong BL, Lorenz JN, Wenisch AS, Levin LS. Evolution of the $m d x$ mouse cardiomyopathy: physiological and morphological findings. Neuromuscul Disord 2004;14:491-6.

[17] Danialou G, Comtois AS, Dudley R, Karpati G, Vincent G, Rosiers Des C, et al. Dystrophin-deficient cardiomyocytes are abnormally vulnerable to mechanical stressinduced contractile failure and injury. FASEB J 2001;15:1655-7.

[18] $\square$ Zhang W, Hove ten M, Schneider JE, Stuckey DJ, SebagMontefiore L, Bia BL, et al. Abnormal cardiac morphology, function and energy metabolism in the dystrophic mdx mouse: An MRI and MRS study. J Mol Cell Cardiol 2008;45:754-60.

[19] Bia BL, Cassidy PJ, Young ME, Rafael JA, Leighton B, Davies KE, et al. Decreased myocardial nNOS, increased iNOS and abnormal ECGs in mouse models of Duchenne muscular dystrophy. J Mol Cell Cardiol 1999;31:1857-62.

$[20] \square$ Chu V, Otero JM, Lopez O, Sullivan MF, Morgan JP, Amende I, et al. Electrocardiographic findings in $m d x$ mice: a cardiac phenotype of Duchenne muscular dystrophy. Muscle Nerve 2002;26:513-9.

[21] Love DR, Hill DF, Dickson G, Spurr NK, Byth BC, Marsden RF, et al. An autosomal transcript in skeletal muscle with homology to dystrophin. Nature 1989;339:55-8.

[22] Deconinck AE, Rafael JA, Skinne JA, Brown SC, Potter AC, Metzinger L, et al. Utrophindystrophin-deficient mice as a model for Duchenne muscular dystrophy. Cell 1997;90:71727.

[23] $\square$ Grady RM, Teng H, Nichol MC, Cunningham JC, Wilkinson RS, Sanes JR. Skeletal and cardiac myopathies in mice lacking utrophin and dystrophin: a model for Duchenne muscular dystrophy. Cell 1997;90:729-38.

[24] Janssen PML. Utrophin deficiency worsens cardiac contractile dysfunction present in dystrophin-deficient $m d x$ mice. Am J Physiol Heart Circ Physiol 2005;289:H2373-8. 


\section{Cellular pathomechanisms in dystrophic cardiomyopathy (JMCC7037)}

[25] $\square$ Megeney LA, Kablar B, Perry RL, Ying C, May L, Rudnicki MA. Severe cardiomyopathy in mice lacking dystrophin and MyoD. Proc Natl Acad Sci U S A 1999;96:220-5.

[26] $\square$ Shelton GD, Engvall E. Canine and feline models of human inherited muscle diseases. Neuromuscul Disord 2005;15:127-38.

[27] Williams IA, Allen DG. Intracellular calcium handling in ventricular myocytes from $m d x$ mice. Am J Physiol Heart Circ Physiol 2006;292:H846-55.

[28] $\square$ Jung C, Martins AS, Niggli E, Shirokova N. Dystrophc cardiomyopathy: amplification of cellular damage by $\mathrm{Ca}^{2+}$ signalling and reactive oxygen species-generating pathways. Cardiovasc Res 2007;77:766-73.

[29] $\square$ Poláková E, Shirokova N. Abnormal sodium handling and mitochondrial metabolism in cardiac dystrophy. Biophys J 2011; abstract.

[30] $\square$ Prosser BL, Ward CW, Lederer WJ. X-ROS signaling: rapid mechano-chemo transduction in heart. Science 2011;333:1440-5.

[31] Ullrich ND, Fanchaouy M, Gusev K, Shirokova N, Niggli E. Hypersensitivity of excitation contraction coupling in dystrophic cardiomyocytes. Am J Physiol Heart Circ Physiol 2009;297:H1992-H2003.

[32] Williams IA, Allen DG. The role of reactive oxygen species in the hearts of dystrophin deficient mdx mice. Am J Physiol Heart Circ Physiol 2007;293:H1969-77.

[33] Bridges LRL. The association of cardiac muscle necrosis and inflammation with the degenerative and persistent myopathy of MDX mice. J Neurol Sci 1986;72:147-57.

[34] $\square$ Millay DP, Sargent MA, Osinska H, Baines CP, Barton ER, Vuagniaux G, et al. Genetc and pharmacologic inhibition of mitochondrial-dependent necrosis attenuates muscular dystrophy. Nat Med 2008;14:442-7.

[35] Deconinck N, Dan B. Pathophysiology of duchenne muscular dystrophy: current hypotheses. Pediatr Neurol 2007;36:1-7.

[36] $\square$ Franco A, Lansman JB. Calcium entry through stretch-inactivated ion channels in mdx myotubes. Nature 1990;344:670-3.

[37] $\square$ Allen DG. Mechanisms of stretchinduced muscle damage in normal and dystrophic muscle: role of ionic changes. J Physiol 2005;567:723-35.

[38] $\square$ Sadeghi A, Doyle AD, Johnson BD. Regulation of the cardiac L-type $\mathrm{Ca}^{2+}$ channel by the actin-binding proteins alpha-actinin and dystrophin. Am $J$ Physiol Cell Physiol 2002;282:C1502-11. 
[39] $\square$ Gervasio OL, Whitehead NP, Yeung EW, Phillips WD, Allen DG. TRPC1 binds to caveolin3 and is regulated by Src kinase - role in Duchenne muscular dystrophy. J Cell Sci 2008;121:2246-55.

[40] Zanou N, Iwata Y, Schakman O, Lebacq J, Wakabayashi S, Gailly P. Essential role of TRPV2 ion channel in the sensitivity of dystrophic muscle to eccentric contractions. FEBS Lett 2009;583:3600-4.

[41] $\square$ Straub V, Rafael JA, Chamberlain JS, Campbell KP. Animal models for muscular dystrophy show different patterns of sarcolemmal disruption. J Cell Biol 1997;139:375-85.

[42] $\square$ Wu G, Majewski J, Ege C, Kjaer K, Weygand M, Lee K. Lipid Corralling and Poloxamer Squeeze-Out in Membranes. Phys Rev Lett 2000;93:028101.

[43] $\square$ Maroto R, Raso A, Wood TG, Kurosky A, Martinac B, Hamill OP. TRPC1 forms the stretch-activated cation channel in vertebrate cells. Nat Cell Biol 2005;7:179-85.

[44] $\square$ Dyachenko V, Husse B, Rueckschloss U, Isenberg G. Mechanical deformation of ventricular myocytes modulates both TRPC6 and Kir2.3 channels. Cell Calcium 2009;45:38-54.

[45] $\square$ Ward ML, Williams IA, Chu Y, Cooper PJ, Ju Y-K, Allen DG. Stretch-activated channels in the heart: contributions to length-dependence and to cardiomyopathy. Prog Biophys Mol Biol 2008;97:232-49.

[46] $\square$ Galbiati F, Volonte D, Chu JB, Li M, Fine SW, Fu M, et al. Transgenic overexpression of caveolin-3 in skeletal muscle fibers induces a Duchenne-like muscular dystrophy phenotype. Proc Natl Acad Sci U S A 2000;97:9689-94.

[47] $\square$ Aravamudan B. Transgenic overexpression of caveolin3 in the heart induces a cardiomyopathic phenotype. Hum Mol Genet 2003;12:2777-88.

[48] $\square$ Millay DP, Goonasekera SA, Sargent MA, Maillet M, Aronow BJ, Molkentin JD. Calcium influx is sufficient to induce muscular dystrophy through a TRPC-dependent mechanism. Proc Natl Acad Sci U S A 2009;106:19023-8.

[49] $\square$ Zhang BT, Whitehead NP, Gervasio OL, Reardon TF, Vale M, Fatkin D, et al. Pathways of $\mathrm{Ca}^{2+}$ entry and cytoskeletal damage following eccentric contractions in mouse skeletal muscle. J Appl Physiol 2012;112:2077-86.

[50] $\square$ Beyder A, Strege PR, Reyes S, Bernard CE, Terzic A, Makielski J, et al. Ranolazine decreases mechanosensitivity of the voltage-gated sodium ion channel NaV1.5: a novel mechanism of drug action. Circulation 2012;125:2698-706. 
[51] $\square$ Petitprez S, Zmoos AF, Ogrodnik J, Balse E, Raad N, EłHaou S, et al. SAP97 and dystrophin macromolecular complexes determine two pools of cardiac sodium channels Nav1.5 in cardiomyocytes. Circ Res 2011;108:294-304.

[52] $\square$ Song MY, Makino A, Yuan JXJ. Role of reactive oxygen species and redox in regulating the function of transient receptor potential channels. Antioxid Redox Signal 2011;15:154965.

[53] $\square$ Fauconnier J, Thireau J, Reiken S, Cassan C, Richard S, Matecki S, et al. Leaky RyR2 trigger ventricular arrhythmias in Duchenne muscular dystrophy. Proc Natl Acad Sci U S A 2010;107:1559-64.

[54] $\square$ Wehrens XHT, Lehnart SE, Reiken S, Vest JA, Wronska A, Marks AR. Ryanodine receptor/calcium release channel PKA phosphorylation: a critical mediator of heart failure progression. Proc Natl Acad Sci U S A 2006;103:511-8.

[55] $\square$ Hæenfuss G, Pieske B. Calcium cycling in congestive heart failure. J Mol Cell Cardiol 2002;34:951-69.

[56] $\square$ Meissner G. Regulation of Ryanodine receptor ion channels through posttranslational modifications. Curr Top Membr 2010;66:91-113.

[57] $\square$ Wehrens XHT, Lehnart SE, Marks AR. Intracellular calcium release and cardiac disease. Annu Rev Physiol 2005;67:69-98.

[58] $\square$ Niggli E, Ullrich ND, Gutierrez D, Kyrychenko S, Poláková E, Shirokova N. Posttranslational modifications of cardiac ryanodine receptors: $\mathrm{Ca}^{2+}$ signaling and ECcoupling. Biochim Biophys Acta 2012:http://dx.doi.org/10.1016/j.bbamcr.2012.08.016.

[59] Venetucci LA, Trafford AW, Eisner DA. Increasing ryanodine receptor openprobability alone does not produce arrhythmogenic calcium waves: threshold sarcoplasmic reticulum calcium content is required. Circ Res 2007;100:105-11.

$[60] \square$ Kyrychenko S, Poláková E, Posscai K, Ullrich ND, Niggli E, Shirokova N. Hypersensitive intracellular $\mathrm{Ca}^{2+}$ signaling precedes deterioration of cardiac functions in muscular dystrophy. Biophys J 2011:abstract.

[61] $\square$ Hidalgo C, Donoso P. Crosstalk between calcium and redox signaling: from molecular mechanisms to health implications. Antiox Redox Signal 2008;10:1275-312.

[62] $\square$ Whitehead NP, Yeung EW, Allen DG. Muscle damage in $m d x$ (dystrophic) mice: role of calcium and reactive oxygen species. Clin Exp Pharmacol Physiol 2006;33:657-62. 
$[63] \square$ Shkryl VM, Martins AS, Ullrich ND, Nowycky MC, Niggli E, Shirokova N. Reciprocal amplification of ROS and $\mathrm{Ca}^{2+}$ signals in stressed $\mathrm{mdx}$ dystrophic skeletal muscle fibers. Pflugers Arch 2009;458:915-28.

[64] Rando TA. Role of nitric oxide in the pathogenesis of muscular dystrophies: a "two hit" hypothesis of the cause of muscle necrosis. Microsc Res Tech 2001;55:223-35.

[65] $\square$ Jiang F, Zhang Y, Dusting GJ. NADPH oxidasemediated redox signaling: roles in cellular stress response, stress tolerance, and tissue repair. Pharmacol Rev 2011;63:218-42.

[66] Martins AS, Shkryl VM, Nowycky MC, Shirokova N. Reactive oxygen species contribute to $\mathrm{Ca}^{2+}$ signals produced by osmotic stress in mouse skeletal muscle fibres. J Physiol 2008;586:197-210.

[67] $\square$ Gul R, Shawl Al, Kim SH, Kim UH. Cooperative interaction between reactive oxygen species and $\mathrm{Ca}^{2+}$ signals contributes to angiotensin II-induced hypertrophy in adult rat cardiomyocytes. Am J Physiol Heart Circ Physiol 2012;302:H901-9.

[68] $\square$ Zhou C. Angiotensin II and stretch activate NADPH oxidase to destabilize cardiac Kv4.3 channel mRNA. Circ Res 2006;98:1040-7.

[69] $\square$ Bellinger AM, Reiken S, Carlson C, Mongillo M, Liu X, Rothman L, et al. Hypernitrosylated ryanodine receptor calcium release channels are leaky in dystrophic muscle. Nat Med 2009;15:325-30.

$[70] \square$ Su JB, Cazorla O, Blot S, BlancharcGGutton N, Mou YA, Barthelemy I, et al. Bradykinin restores left ventricular function, sarcomeric protein phosphorylation, and e/nNOS levels in dogs with Duchenne muscular dystrophy cardiomyopathy. Cardiovasc Res 2012;95:86-96.

[71] $\square$ Hammond J, Balligand $\mathrm{HL}$. Nitric oxide synthase and cyclic GMP signaling in cardiac myocytes: from contractility to remodeling. J Mol Cell Cardiol 2012;52:330-40.

[72] $\square$ Khairallah M, Khairallah RJ, Young ME, Allen BG, Gillis MA, Danialou G, et al. Sildenafil and cardiomyocyte-specific cGMP signaling prevent cardiomyopathic changes associated with dystrophin deficiency. Proc Natl Acad Sci U S A 2008;105:7028-33.

[73] $\square$ George $\mathrm{CH}$, Jundi $\mathrm{H}$, Thomas NL, Scoote M, Walters N, Williams AJ, et al. Ryanodine receptor regulation by intramolecular interaction between cytoplasmic and transmembrane domains. Mol Biol Cell 2004;15:2627-38.

[74] $\square$ Sarma S, Li N, van Oort RJ, Reynolds C, Skapura DG, Wehrens XHT. Genetic inhibition of PKA phosphorylation of RyR2 prevents dystrophic cardiomyopathy. Proc Natl Acad Sci U S A 2010;107:13165-70. 
[75] $\square$ Erickson JR, Joiner MLA, Guan X, Kutschke W, Yang J, Oddis CV, et al. A dynamic pathway for calcium-independent activation of CaMKII by methionine oxidation. Cell 2008;133:462-74.

[76] $\square$ Ather S, Wang W, Wang Q, Li N, Wehrens XHT. Inhibition of CaMKII phosphorylation of RyR2 prevents ventricular tachycardia in Duchenne Muscular Dystrophy. Circulation 2010: abstract. 


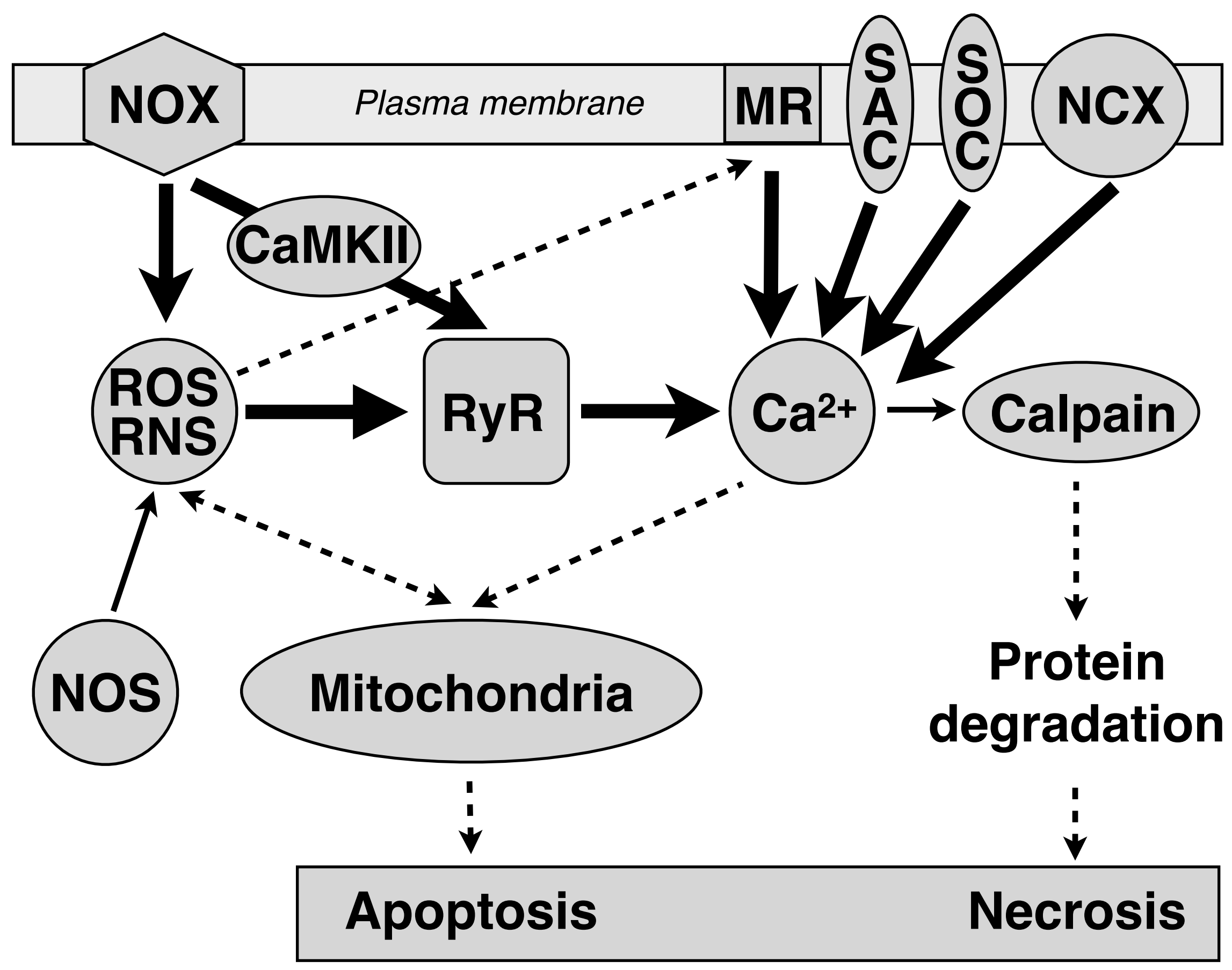

Diagram 1 


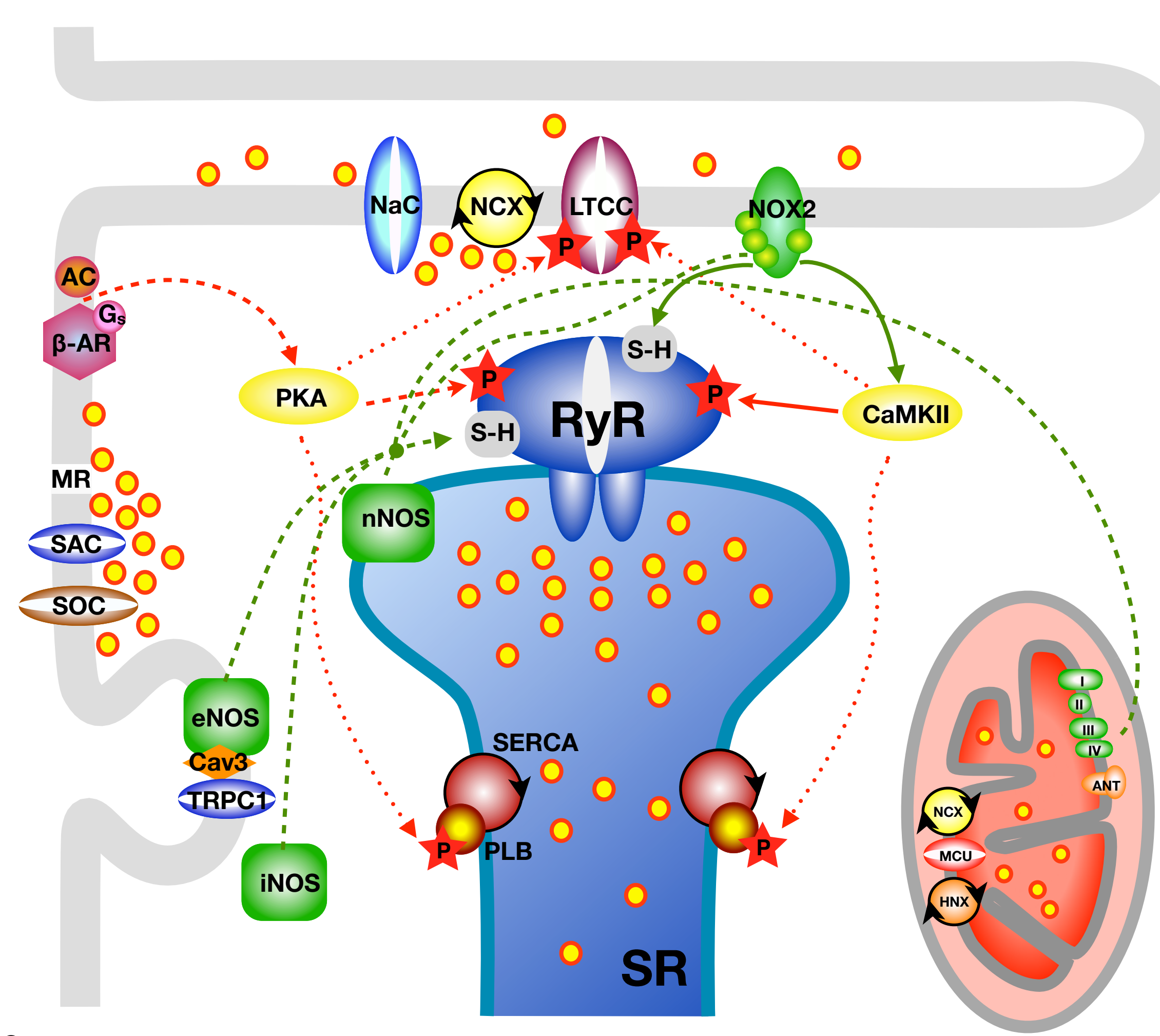

Diagram 2 